\title{
A Utilização do Ambiente Virtual de Aprendizagem Sócrates na Educação Básica: Um caminho de Reconstrução da Prática Pedagógica
}

\author{
José Ivan Gadelha da Rocha Junior ${ }^{1}$, Eliana Alves Moreira Leite ${ }^{2}$, Gilvandenys \\ Leite Sales ${ }^{3}$, Adriano Silveira Machado ${ }^{2}$, Delano Cândido ${ }^{1}$ \\ ${ }^{1}$ Universidade Federal do Ceará, Instituto UFC Virtual - Fortaleza, CE - Brasil. \\ ${ }^{2}$ Secretaria Municipal da Educação de Fortaleza - Fortaleza, CE - Brasil. \\ ${ }^{3}$ Instituto Federal do Ceará - Fortaleza, CE - Brasil.
}

\{ivanrocha83,elimoreiraead, denyssales, adrianomachado2007, delano.candido\}@gmail.com

\begin{abstract}
This work seeks to analyze the use of Information and Communication Technologies contained in a Virtual Learning Environment, as well as its possibilities of pedagogical exploration for the improvement of the teaching process of the Geography discipline. The approach of the object of study was the need to change traditional teaching practice, and the need to articulate to the traditional methodology a collaborative teaching model that has the pedagogical potential of making teaching practice more dynamic, collaborative and cooperative, capable of Generate co-learning, giving rise to new learning situations and an additional method of managing them.
\end{abstract}

Resumo. Este trabalho busca analisar a utilização de Tecnologias Digitais de Informação e Comunicação contidas em um Ambiente Virtual de Aprendizagem, bem como suas possibilidades de exploração pedagógica para a melhoria do processo de ensino da disciplina de Geografia. A aproximação do objeto de estudo deu-se com a necessidade de mudança da prática docente tradicional, e a necessidade de articular à metodologia tradicional um modelo de ensino colaborativo que possui o potencial pedagógico de tornar a prática docente mais dinâmica, colaborativa e cooperativa, capaz de gerar coaprendência, originando novas situações de aprendizagem e um método adicional de seu gerenciamento.

\section{Introdução}

Apesar dos avanços das tecnologias digitais, é notório que a utilização de Ambientes Virtuais de Aprendizagem (AVA) e de recursos tecnológicos na educação, ainda é um grande desafio, seja pela carência de formação docente ou pela deficiência infraestrutural para garantir sua exploração em ambientes de aprendizagem nas escolas.

Pesquisadores, que se dedicam aos seus estudos, trabalham com possibilidades de inovação de práticas pedagógicas, que se somam às já existentes e se consolidam, 
influenciadas pelo advento da cibercultura [Mattar 2013, Messa 2010, Morais e Cabrita 2010, Pereira, Schmitt e Dias 2007]. Seja num simples material impresso ou na apresentação completa de um ambiente virtual de aprendizagem, a comunicação visual contida no design gráfico deve ser planejada para atender aos objetivos desejados.

Hoje, essa comunicação visual é influenciada pelos recursos das tecnologias digitais da informação e comunicação (TDIC) que, como citado anteriormente, têm sua utilização cada vez mais popularizada com o advento da cibercultura, e favorece o processo de formação pedagógica, a partir de aulas mais intertextuais e hipermidiáticas.

No campo do ciberespaço, os AVA trazem novas possibilidades de reflexão acerca de práticas educativas já consolidadas. A aprendizagem passa a ter uma característica cada vez mais colaborativa, devido às formas de interação que se desenvolvem, ora de forma síncrona, ora de forma assíncrona.

Esses AVA apoiaram-se na evolução da web 2.0, o que permitiu sua estruturação por meio de softwares e um conjunto de ferramentas com um maior poder de comunicação e interação, consolidando-se como um espaço de compartilhamento de informações em redes mediadas por sistemas digitais, pela mudança e encontro de mídias, dos computadores e outros dispositivos portáteis como a telefonia móvel.

Nesses ambientes, é notório que a linguagem midiática possa ser capaz de auxiliar a realização de múltiplas tarefas que no modelo tradicional é desempenhada pelo professor. E mesmo assim a mediação do professor é importante para que a informação seja transformada em conhecimento. A contribuição do professor para o processo de formação pedagógica ocorre a partir de aulas mais intertextuais, hipermidiáticas e coautorais, em que há coensino e coaprendência.

Com os recursos das Tecnologias Digitais da Informação e Comunicação (TDIC) e com a ampliação e aprimoramento dos AVA, temos um quadro em que os conteúdos e habilidades dos currículos passam por uma necessidade de reconstrução e aperfeiçoamento da linguagem utilizada. Percebe-se então a intuição de contribuir para aprendizagens colaborativas conectadas com recursos hipermidiáticos considerando a introdução de novas formas de transmissão de conhecimento a partir da tecnologia.

Este trabalho tem como objetivo mostrar o resultado da aplicação de uma proposta metodológica que é a utilização de um AVA como uma estratégia de inovação pedagógica para a transmissão de conteúdos no ensino fundamental, tomando por base a disciplina de Geografia ( $9^{\circ}$ ano).

Com isso, busca-se apreender se a utilização de tecnologias aplicadas na educação possibilita uma aprendizagem mais dinâmica, ao proporcionar uma maior interação entre professores e alunos diante dos conteúdos científicos trabalhados na elaboração de pesquisas em grupo.

É indiscutível afirmar que as transformações verificadas na evolução da sociedade causadas pelo avanço das tecnologias digitais da informação e comunicação na escola são responsáveis pelo desenvolvimento da Ciência e das relações humanas.

Para aplicação destas tecnologias, é necessário um processo de formação continuada de professores que capacite não somente para a utilização da técnica, mas 
VI Congresso Brasileiro de Informática na Educação (CBIE 2017)

Anais do XXIII Workshop de Informática na Escola (WIE 2017)

principalmente, estimule novas metodologias de comunicação, interação e aprendizagem [Moreira 2005].

Levando em consideração as teorias construtivistas da aprendizagem, é possível identificar como ocorre o processo de intervenção pedagógica entre os atores que participam diretamente do processo de ensino e aprendizagem, a partir da utilização de tecnologias. Segundo Lins (2003):

\begin{abstract}
A teoria de Piaget prioriza a interação entre sujeito e objeto e destaca que o crescimento cognitivo se dá a partir da ação do indivíduo sobre o objeto de seu conhecimento. Na abordagem socioconstutivista, de Vygotsky, a interação social, a cultura e a linguagem exercem forte influência sobre a aprendizagem, como fatores importantes para a formalização de conceitos e para a configuração da estrutura mental.
\end{abstract}

Nesse aspecto, para ambas as teorias, a aprendizagem acontece a partir de trocas de experiências, sendo essas, elementos indispensáveis no desenvolvimento dos aprendizes. Assim, a aprendizagem acontece a partir da exploração das tecnologias disponíveis, por meio de atividades que permitam a colaboração entre os alunos e a coparticipação desses, com os professores. Em ambientes virtuais, a gestão da aprendizagem faz-se por meio de ferramentas que colocam o aluno em contato direto com o professor. Isso responde às necessidades da nova dinâmica que envolve $o$ processo de ensino e aprendizagem, que nos dias atuais, está cada vez mais influenciado pela evolução da tecnologia, fato esse responsável por criar condições para uma aprendizagem significativa.

Nesse sentido, faz-se necessário uma revisão quanto à metodologia de ensino utilizada como prática pedagógica pelo professor, que melhor satisfaça as condições para a efetivação de uma aprendizagem significativa, utilizando estratégias que favoreçam, além da compreensão dos conteúdos selecionados, a sua internalização pelos alunos.

\title{
2. Tecnologias digitais como suporte a aprendizagem
}

Similarmente à pesquisa a ser apresentada neste artigo, cita-se o trabalho empreendido por Costa et al. (2016) sobre o uso de ambientes virtuais e a importância dos feedbacks dos professores no processo de aprendizagem. Mesmo havendo uma carência significativa de tipologias de feedback aos alunos usuários de plataformas, os autores entendem que o acompanhamento das atividades colaborativas em tempo hábil, atua como instrumento de mediação pedagógica imprescindível para as apreensões dos alunos.

Isto vem corroborar com a premissa de uso do AVA, no instante em que professor e alunos envolvidos nas ações colaborativas e construções hipertextuais interatuam, trocam informações, impressões, reveem conceitos, teorias e hipóteses estudadas, o que vem permitir um implemento considerável à qualidade dos trabalhos em equipe.

Da mesma maneira Acosta, Reategui e Behar (2016) optaram por investigar a relevância pedagógica da aprendizagem baseada na proposição de projetos com apoio de um AVA. O estudo revelou-se vital para o desenvolvimento de projetos de pesquisa, bem como para a qualidade da interação e colaboração entre alunos. 
Já Ferreira, Werneck e Santos (2016) apontam em seu estudo a necessidade de ampliar as pesquisas envolvendo os ambientes virtuais de aprendizagem e as estratégias empregadas no processo de avaliação dos alunos-usuários, como também destacam a relevância do processo de avaliação dos alunos-usuários das plataformas para o desenvolvimento do processo de ensino e, por conseguinte da aprendizagem.

Há um ponto em comum na visão de diferentes autores que pesquisam sobre tecnologia na educação. Todos defendem a ideia de que a utilização de tecnologias no sistema educacional, desde que feita de maneira planejada, podem trazer benefícios para o ensino, tornando as atividades desenvolvidas em sala de aula, mais atrativas.

Leite et al. (2013) apresentam a reestruturação de um curso no AVA Moodle com metodologia envolvendo fóruns de discussão estruturados com tema gerador e questionamentos norteadores e quizzes planejados para fazer valer uma avaliação assistida com seus feedbacks reguladores. Empregaram como ferramenta de avaliação formativa o Modelo Learning Vectors (Modelo LV). Os resultados revelam uma redução da evasão e menor sobrecarga de trabalho dos tutores tendo em vista que as turmas eram numerosas.

Desta maneira entende-se que o uso pedagogicamente adequado das tecnologias digitais de informação e comunicação, podem representar estratégias adicionais para o professor em sala de aula, que através da mediação, trabalho direcionado, sugestão e direcionamentos de pesquisa, encontrará mecanismos favoráveis às apreensões e reconstruções de conhecimento científico, seja ele basilar ou mais complexo.

A seguir apresenta-se a metodologia desse trabalho.

\section{Métodos}

A pesquisa se encaixa na abordagem qualitativa, e permite observar o envolvimento e motivação dos estudantes em relação aos conteúdos da disciplina de Geografia e indicar que ações podem ser direcionadas para uma melhor aprendizagem. Tem caráter experimental porque permite ao investigador visualizar a técnica que garanta maior eficácia do ensino.

A pesquisa de campo foi desenvolvida na Escola Municipal de Tempo Integral no município de Fortaleza/CE, com uma turma de $9^{\circ}$ ano do ensino fundamental com um total de 24 alunos regularmente matriculados. A investigação ocorreu durante as aulas de Geografia, auxiliadas pelos computadores instalados no Laboratório de Informática da escola. O laboratório contava com o suporte técnico do laboratorista e professor da disciplina.

Foi utilizado como recurso tecnológico adicional à pesquisa, o Ambiente Virtual Sócrates, uma plataforma virtual de ensino que oportuniza a utilização de recursos e ferramentas educacionais que permitem a construção de uma aprendizagem colaborativa dentro do ambiente virtual. Nessa plataforma de ensino, é possível participar de comunidades, projetos, bem como desenvolver cursos específicos por meio de autorização prévia da equipe técnica, após a avaliação e validação do curso solicitado.

O Ambiente Virtual Sócrates, simula uma sala de aula virtual, disponibilizando ao professor, ferramentas de interação e interatividade tais como agenda, calendário, fórum, portfólio, acompanhamento, matrícula, participantes, aulas, mensagens dentre 
outros. Para se trabalhar os conteúdos da disciplina de Geografia dentro do ambiente virtual, foi necessária a produção de material didático que transportasse os conteúdos trabalhados no livro para dentro do ambiente virtual.

A utilização da linguagem digital permitiu a ampliação do poder de comunicação ao trabalhar, além de textos, com imagens, infográficos, links e vídeos que ampliavam o acesso aos conteúdos trabalhados pelo professor.

O curso foi montado a partir dos conteúdos contemplados nos capítulos 9 e 10 do livro texto adotado pela escola, trazendo dois eixos temáticos a serem explorados durante os bimestres: África e Oceania. Após uma breve exposição teórica dos conteúdos, eram exploradas atividades que contavam com o suporte dos recursos e ferramentas disponibilizadas no AVA.

Para cada aula, eram realizadas atividades de leitura dinâmica na qual os alunos tinham a oportunidade de explorar todo o conteúdo hipermidiático contido. Em seguida, os alunos eram levados a participarem de atividades de fórum de discussão e portfólio. Nos fóruns, eram levantadas discussões que permitiam ao professor, a visualização do nível de percepção e aprendizagem que os alunos estavam tendo da matéria, bem como a percepção de algumas necessidades de intervenções em questionamentos e opiniões levantados pelos mesmos.

Era possível também, ampliar a visão geral do conteúdo estudado por meio do estímulo à pesquisa em outras páginas da internet, no qual os alunos compartilhavam entre si, links que faziam referência a textos, imagens e vídeos relacionados àqueles conteúdos. Percebeu-se uma participação considerável dos alunos pelo envolvimento pessoal de cada um nas discussões propostas.

Além de postagens que respondiam a proposta inicial de discussão do fórum, os alunos elaboravam questionamentos que eram direcionados especificamente para alguns dos participantes da atividade, mas que podiam ser respondidos por qualquer outro que se interessasse em participar da discussão.

Com isso, a turma demonstrou um bom nível de interação que ampliava a proposta inicial da discussão, chegando, em alguns casos, a fazer referências a outros temas transversais.

Outra ferramenta bastante explorada durante a aplicação da metodologia de ensino utilizando o AVA para a disciplina de Geografia foi a ferramenta portfólio. Por meio dessa ferramenta, o professor teve a oportunidade de trabalhar juntamente aos alunos o incentivo para construção de um acervo de atividades de pesquisa e registro das mesmas em sua pasta pessoal. A aplicação dessa atividade era previamente realizada por meio da edição e escrita colaborativa no Google Docs (Figura 1), que, depois de finalizada, era transposta para a pasta de portfólio dentro do AVA. 
VI Congresso Brasileiro de Informática na Educação (CBIE 2017)

Anais do XXIII Workshop de Informática na Escola (WIE 2017)

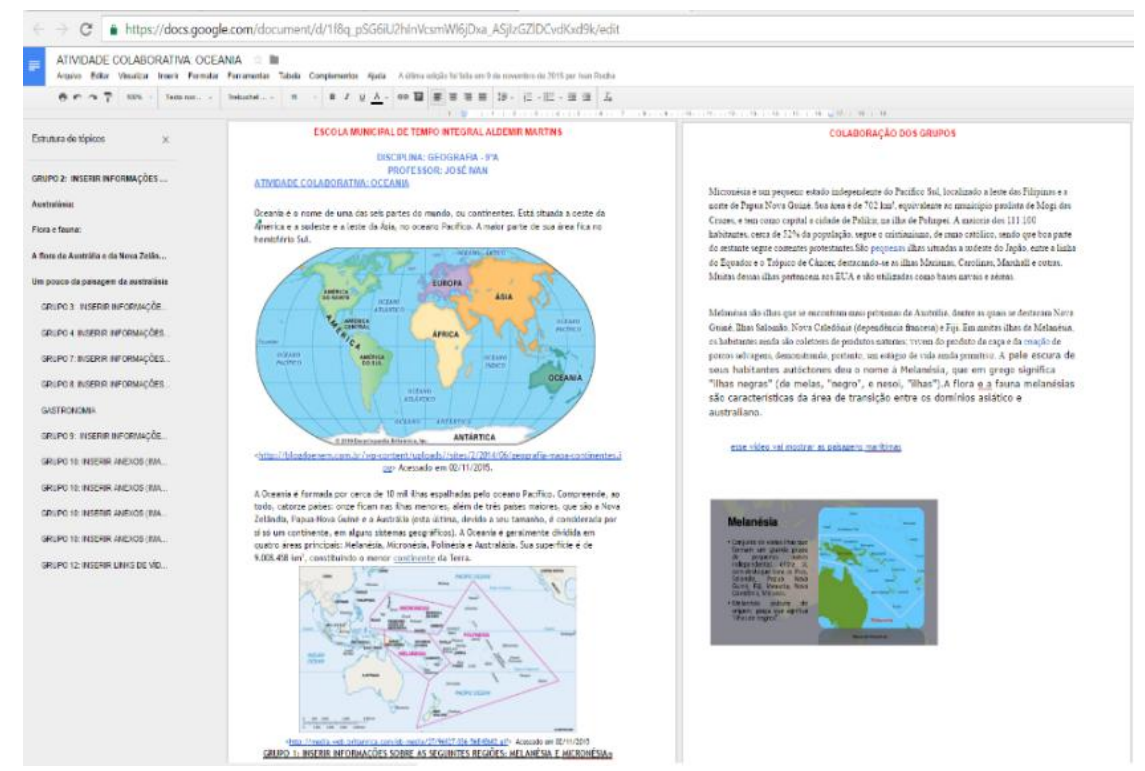

Figura 1. Escrita colaborativa (Google Docs)

O desenvolvimento da atividade se deu em três etapas distintas e interligadas:

- $1^{\circ}$ passo: O professor edita um documento no Google Docs e compartilha com cada aluno, por meio de seu endereço de e-mail, dando a ele, o poder de edição do documento. Pedia-se que fosse realizado um trabalho de pesquisa e registro das mesmas com as devidas referências. A atividade devia ser feita em dupla, na qual cada um dos membros da dupla ficaria responsável por uma determinada parte da edição do trabalho, gerando ao final, um texto colaborativo.

- $\quad 2^{\circ}$ passo: Os alunos, divididos em equipes, pesquisavam e publicavam o material recolhido dentro do texto colaborativo elaborado. As pesquisas estavam divididas em textos, imagens e hiperlinks, conferindo ao material produzido um formato de hipertexto.

- $3^{\circ}$ passo: O professor fazia uma revisão da formatação padronizada do texto final e, após avaliação, autorizava a publicação do trabalho dentro da pasta de portfólio individual do aluno no AVA (Figura 2).

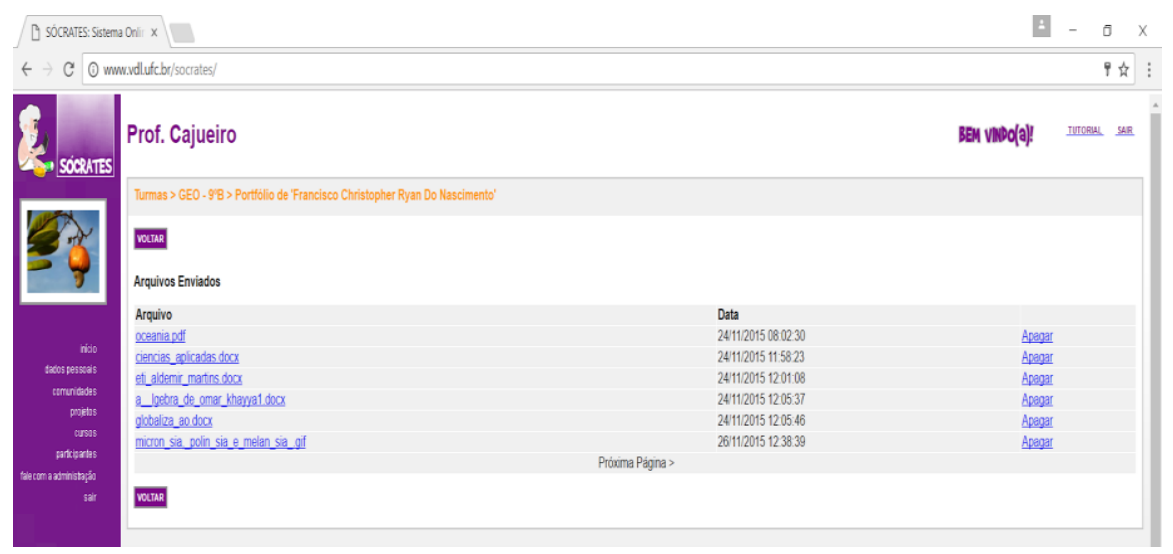

Figure 2. Pasta de portfólio individual 
Como resultado final da proposta dessa atividade, o professor visualizou o processo de construção colaborativa das atividades, explorou a contribuição que cada um deu ao trabalho, fazendo com que os alunos visualizassem o trabalho por etapas. Isto foi importante para que cada aluno participante do trabalho percebesse a construção e colaboração individual e coletiva, refletindo sobre a importância do trabalho em equipe para aprendizagem do outro, colocando dessa maneira, a prática do exercício da interação, cooperação e partilha.

Trata-se na próxima seção da análise dos dados levantados nessa pesquisa.

\section{Resultados e Discussão}

A pesquisa desenvolvida no AVA Sócrates com 24 estudantes da turma do $9^{\circ}$ ano do ensino fundamental proporcionou uma reflexão conjunta sobre a construção de trabalhos em equipe, a troca de experiências, o relato de situações vivenciadas, a testagem e refutação de hipóteses na melhoria do processo de ensino e na aprendizagem dos conteúdos da área de Geografia.

O trabalho coparticipativo e interativo permitiu um incremento no rendimento da referida disciplina, quando comparado à etapa na qual não houve emprego do AVA para suporte ao processo de ensino e aprendizagem de conteúdos escolares. Afirma-se isso pelo fato de que as avaliações da escola onde se aplicou a pesquisa estão divididas em quatro bimestres, sendo que a plataforma foi utilizada a partir do segundo semestre.

Isso permitiu uma comparação do rendimento, em termos de notas, dos estudantes antes e depois do emprego do AVA como complementação a metodologia do ensino e da mediação pedagógica docente (Tabela 1).

Tabela 1 - Rendimentos por bimestre da disciplina de Geografia (9a ano/2015)

\begin{tabular}{|l|c|c|c|c|}
\hline \multirow{2}{*}{ RENDIMENTOS } & \multicolumn{4}{|c|}{ NÚMERO DE ESTUDANTES } \\
\cline { 2 - 5 } & $\mathbf{1 0}$ Bimestre & 20 Bimestre & 3o Bimestre & $\mathbf{4}^{\circ}$ Bimestre \\
\hline Abaixo da média & 16 & 09 & 07 & 04 \\
\hline Na média & 04 & 08 & 04 & 06 \\
\hline Acima da média & 08 & 08 & 13 & 14 \\
\hline Total de estudantes & 28 & 25 & 24 & 24 \\
\hline
\end{tabular}

Fonte: Elaborada pelo autor

Antes do uso do AVA, no primeiro bimestre do total de alunos, 42,9\% tiveram rendimentos que atingiram a nota mínima para aprovação, já $28,6 \%$ apresentaram notas acima da média e $14,3 \%$ com notas na média.

Ao se comparar os dados obtidos com os resultados encontrados no segundo bimestre, 64\% atingiram nota satisfatória para aprovação, 32\% alcançaram notas acima da média e 32\% dos alunos encontravam-se com notas iguais à média mínima esperada.

Após a utilização do AVA, no terceiro bimestre 70,8\% dos estudantes alcançaram rendimentos necessários para aprovação. Do total, 54,2\% com notas acima da média e 16,6\% com notas na média.

Esse resultado positivo repetiu-se no quarto bimestre, comprovando que o uso pedagogicamente orientado de recursos tecnológicos se mostra também eficiente 
VI Congresso Brasileiro de Informática na Educação (CBIE 2017)

Anais do XXIII Workshop de Informática na Escola (WIE 2017)

enquanto estratégia de ensino, que unifica a procedimentos de cunho metodológico tradicional de ensino a uma prática de mediação pedagógica com recursos tecnológicos (Gráfico 1).

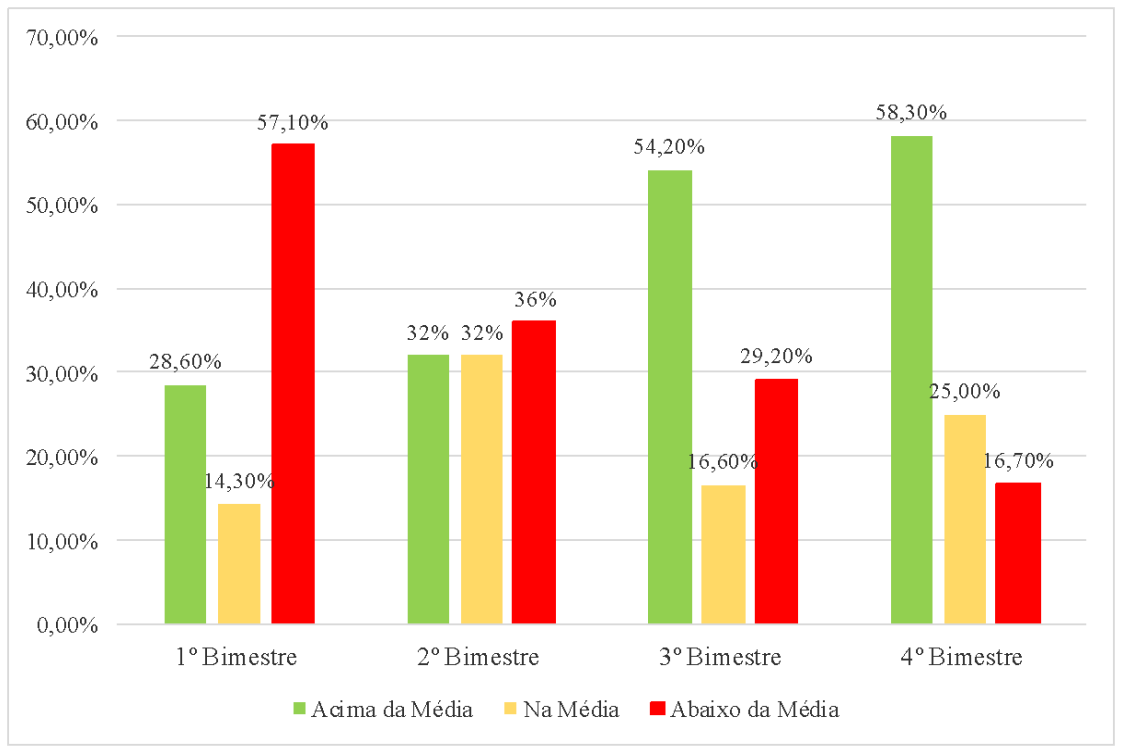

Gráfico 1 - Comparação de rendimentos por bimestre em 2015

Fonte: Elaborado pelo autor

Dessa forma, nota-se que com o uso do AVA, como ferramenta de apoio ao ensino, há um aumento do número de estudantes com notas na média e acima da média a partir da utilização do AVA Sócrates.

A seguir, traçam-se as considerações finais.

\section{Conclusões}

Verificou-se que a utilização do AVA Sócrates como ferramenta pedagógica promoveu uma melhoria da aprendizagem dos alunos. $\mathrm{O}$ resultado alcançado com a evolução das participações, debates, trabalho colaborativo e os aspectos quantitativos apresentados pelos alunos durante o percurso das atividades desenvolvidas é reflexo de uma nova proposta de ensino, baseada na utilização de tecnologias, que permitiu maior aceitação das leituras referentes ao assunto da disciplina e consequentemente, desenvolver uma maior motivação para participar das atividades propostas.

Ao aplicar essa metodologia como professor da disciplina supracitada foi possível perceber que o AVA colaborou com práticas de ensino mais dinâmicas, que proporcionaram maior interação entre professor, alunos e conteúdos. As temáticas presentes no livro didático passaram a ter uma abordagem ampliada, na medida em que outros recursos, além do texto, foram disponibilizados pelo professor. Recursos como vídeos, infográficos, imagens, sites de pesquisas, entre outros, que proporcionam a criação de hipertextos. Estes permitem uma maior exploração dos conteúdos abordados na disciplina.

A partir da maior interatividade proporcionada com as matérias estudadas, foi observada uma mudança de comportamento dos alunos, que passaram a ter maior motivação para participar das aulas de geografia. Além disso, com a utilização do AVA 
os alunos tiveram a possibilidade de ter um papel mais ativo nas aulas, podendo sugerir atividades juntamente ao professor diante das pesquisas realizadas por eles próprios.

Dessa forma, com o uso do ambiente virtual os estudantes tornaram-se mais participativos a partir do momento em que traziam curiosidades, dicas de sites, compartilhavam materiais de maneira colaborativa entre si e com o professor. Isso permitiu mais atenção e responsabilidade diante dos conteúdos, pois os mesmos queriam mostrar e compartilhar os resultados de suas atividades individuais, contribuindo com o aprendizado do grupo.

O AVA serviu como complemento às aulas trabalhadas anteriormente de maneira expositiva em sala de aula. Pode-se concluir que a melhoria dos rendimentos na disciplina de Geografia, visualizada a partir do terceiro e quarto bimestre, conforme demonstrada no Gráfico 1, está associada diretamente a utilização do AVA Sócrates e da possibilidade de se trabalhar com recursos hipermidiáticos.

O conhecimento prévio dos alunos também deve ser levado em consideração nessa melhoria, pois o domínio sobre a interação e interatividade no ambiente favoreceu para que os mesmos tivessem um bom desempenho nas atividades propostas. Isso contribuiu para que fosse colocado em prática, a vivência de atividades cooperativas e colaborativas dentro do ambiente virtual, trazendo contribuições significativas para a criação de novas situações de aprendizagem que tinham a capacidade de despertar nos alunos, uma maior motivação para participação ativa.

Enfim, pode-se destacar como resultados desta pesquisa: a promoção de uma melhoria do processo de ensino e aprendizagem e inovação na prática pedagógica para a disciplina de Geografia; o aproveitamento maior do potencial das tecnologias digitais disponíveis e o desenvolvimento de habilidades de pesquisa dirigida na web, a fim de despertar nos alunos um maior interesse pelos conteúdos da disciplina de Geografia; e, a promoção de uma maior interação, colaboração e cooperação na realização das atividades propostas.

Propõem-se em trabalhos futuros fazer uso de elementos de jogos na sala de aula virtual, ou seja, gamificar o AVA e analisar seus efeitos.

\section{Referências}

AVA Sócrates. Disponível em: < http://www.vdl.ufc.br/socrates/> Acessado em: 12 nov 2016

Acosta, O.; Reategui, E.; Behar, P. A. (2016). "Recomendação de Conteúdo em um Ambiente Colaborativo de Aprendizagem Baseada em Projetos". In: Anais dos Workshops do V Congresso Brasileiro de Informática na Educação (CBIE).

Costa, E.; Fechine, J.; Silva, P.; Rocha, H. (2016). "Modelos de Feedback para estudantes em Ambientes Virtuais de Aprendizagem". In: V Jornada de Atualização em Informática na Educação (JAIE).

Ferreira, A. A.; Werneck, V. M. B.; Santos, N. (2016). “Avaliação da Aprendizagem em Ambientes Educacionais: Uma Revisão Sistemática”. In: Anais do XXVII Simpósio Brasileiro de Informática na Educação (SBIE). 
VI Congresso Brasileiro de Informática na Educação (CBIE 2017)

Anais do XXIII Workshop de Informática na Escola (WIE 2017)

Leite, E. A. M., Sales, G. L., Lima, H. V. e Aguiar, Eveline P. S. (2013). "Reestruturação do Curso de Formação em Conselhos Escolares no AVA Moodle por meio do Design Instrucional". In: Anais do XIX Workshop de Informática na Escola (WIE).

Lins, S. (2003). Transferindo conhecimento tácito: uma abordagem construtivista. Rio de Janeiro: E-papers, 2003.

Mattar, J. (2013). Aprendizagem em ambientes virtuais: teorias, conectivismo e MOOCs. São Paulo: TECCOGS-PUC/SP, n. 7, p. 21-40.

Messa, W. C. (2010). Utilização de ambientes virtuais de aprendizagem - AVAs: a busca por uma aprendizagem significativa. Revista Brasileira de Aprendizagem Aberta e a Distância, v. 9, p. 01-49.

Morais, N. S. e Cabrita, I. (2010). Ambientes virtuais de aprendizagem: comunicação (as) síncrona e interação no ensino superior. Revista PRISMA. COM, n. 6.

Moreira, G. M. de O. (2005). "Tecnologias de informação e comunicação na escola pública: sentidos produzidos na formação continuada de professores". Porto Alegre : UFRGS, f. Dissertação (mestrado).

Pereira, A., Schmitt, V e Dias, R. (2007). “Ambientes virtuais de aprendizagem”. In: PEREIRA, A. (Org.). Ambientes virtuais de aprendizagem em diferentes contextos. Rio de Janeiro: Editora Ciência Moderna Ltda. 